\title{
Schizophrenia relapse, patient considerations, and potential role of lurasidone
}

\author{
This article was published in the following Dove Press journal: \\ Patient Preference and Adherence \\ 9 August 2016 \\ Number of times this article has been viewed
}

\section{Leslie Citrome}

Department of Psychiatry and Behavioral Sciences, New York Medical College, Valhalla, NY, USA
Correspondence: Leslie Citrome I I Medical Park Drive, Suite 106, Pomona, NY 10970, USA

$\mathrm{Tel}+$ I 845362208 |

Fax +I 8453628745

Email citrome@cnsconsultant.com

\begin{abstract}
When treating persons with schizophrenia, delaying time to relapse is a main goal. Antipsychotic medication has been the primary treatment approach, and there are a variety of different choices available. Lurasidone is a second-generation (atypical) antipsychotic agent that is approved for the treatment of schizophrenia and bipolar depression. Three long-term studies of lurasidone have examined time to relapse in persons with schizophrenia, including a classic placebo-controlled randomized withdrawal study and two 12-month active comparator studies (vs risperidone and vs quetiapine extended-release). Lurasidone 40-80 mg/d evidenced superiority over placebo (number needed to treat [NNT] vs placebo for relapse, 9). Lurasidone $40-160 \mathrm{mg} / \mathrm{d}$ was noninferior to quetiapine extended-release $200-800 \mathrm{mg} / \mathrm{d}$ on the outcome of relapse, and was superior on the outcome of avoidance of hospitalization (NNT 8) and the outcome of remission (NNT 7). Lurasidone demonstrated a lower risk for long-term weight gain than the active comparators. Demonstrated differences in tolerability profiles among the different choices of antipsychotics make it possible to attempt to match up an individual patient to the best choice for such patient based on past history of tolerability, comorbidities, and personal preferences, potentially improving adherence.
\end{abstract}

Keywords: antipsychotic, lurasidone, relapse, tolerability, schizophrenia, weight gain

\section{Introduction}

Optimal management of schizophrenia requires adequate symptom control and avoidance of exacerbation or relapse. Unfortunately, relapse is common, with an estimate of $\geq 80 \%$ of patients experiencing a relapse in their first 5 years of treatment. ${ }^{1}$ Delaying time to relapse is a primary goal when using antipsychotic medication, and may mitigate against further decline. ${ }^{2}$ Lifelong use of antipsychotic medication is thus required. ${ }^{3}$ Unfortunately, antipsychotic medications are associated with a myriad of adverse effects. ${ }^{4,5}$ Demonstrated differences in tolerability profiles among the different choices of antipsychotics ${ }^{6}$ make it possible to attempt to match up an individual patient to the best choice for such patient based on past history of tolerability, comorbidities, and personal preferences. ${ }^{7,8}$

Lurasidone is a second-generation (atypical) antipsychotic agent that has demonstrated efficacy in the treatment of patients with schizophrenia, and it is approved as such in the United States, Canada, the European Union, Switzerland, and Australia; it is also approved in the United States and Canada for the treatment of major depressive episodes associated with bipolar I disorder as either a monotherapy or adjunctive therapy with lithium or valproate..$^{9}$ Lurasidone's pharmacodynamic profile is distinguished by its relatively high affinity for serotonin 5-HT7 receptors and its partial agonist activity at 5-HT1A receptors, together with being a full antagonist at 
dopamine D2 and serotonin 5-HT2A receptors. ${ }^{9}$ Lurasidone's pharmacokinetic profile permits once-daily dosing, and administration needs to be with food; it is recommended that lurasidone be taken once daily in the evening, with a meal or within 30 minutes after eating. ${ }^{9}$ Metabolism is primarily via CYP3A4 and, consequently, its use is contraindicated in the presence of strong inhibitors or inducers of CYP3A4 such as ketoconazole or rifampin, respectively. ${ }^{9}$ Lurasidone appears associated with minimal effects on body weight and low risk for clinically meaningful alterations in glucose, lipids, or electrocardiogram parameters. ${ }^{9}$

This review examines the lurasidone data regarding relapse prevention in persons with schizophrenia, specifically appraising the results from double-blind controlled trials.

\section{Methods}

A literature search was conducted on June 14, 2016, using the following terms "lurasidone AND relapse" using the US National Library of Medicine PubMed.gov resource. A total of 22 records were found, of which three were primary reports of double-blind randomized trials, ${ }^{10-12}$ and one was an economic evaluation ${ }^{13}$ of one of the studies reported. ${ }^{11}$ One of the studies was a classic randomized withdrawal placebocontrolled relapse prevention study, ${ }^{12}$ whereas the other two studies compared lurasidone with quetiapine extended-release $(\mathrm{XR})^{11}$ and risperidone. ${ }^{10}$ These reports, ${ }^{10-12}$ together with any study results posted on the ClinicalTrials.gov registry, were the principal information sources for this review.

\section{Results}

Table 1 provides an overview of the three relevant studies: Citrome et al, ${ }^{10}$ Loebel et al, ${ }^{11}$ and Tandon et al. ${ }^{12}$ Doses of lurasidone tested were in the range of $40-160 \mathrm{mg} / \mathrm{d}$.

\section{NCT0064I 745}

The first published randomized double-blind study of lurasidone that included relapse as an outcome measure was a 12-month safety and tolerability study where 629 persons, aged between 18 and 75 years, with clinically stable schizophrenia or schizoaffective disorder, were allocated to receive flexibly dosed lurasidone $40-120 \mathrm{mg} / \mathrm{d}(\mathrm{n}=427)$ or risperidone $2-6 \mathrm{mg} / \mathrm{d}(\mathrm{n}=202) .{ }^{10}$ The study was conducted at 68 study centers located primarily in the United States (40 sites; approximately two-thirds of all participants), but also recruited patients in Argentina, Brazil, Chile, Croatia, Israel, South Africa, and Thailand. Inclusion criteria included the following: duration of illness $\geq 1$ year; in a nonacute phase of illness for $\geq 8$ weeks; no change in antipsychotic medications, other than minor dose adjustments for tolerability purposes, for $\geq 6$ weeks before screening; no hospitalization for psychiatric illness for $\geq 8$ weeks; and moderate or less severity rating on the Positive and Negative Syndrome Scale (PANSS) items of delusions, conceptual disorganization, hallucinations, and unusual thought content. Among the exclusion criteria were treatment with risperidone within 6 weeks before baseline, or a history of a poor or an inadequate response, or intolerability to risperidone. Patients who had been treated with a stable dose of antidepressants or mood stabilizers for $\geq 1$ month before the baseline visit were allowed to continue this treatment during the study; otherwise, subjects were not permitted to begin treatment with these agents after the screening visit. Although the primary outcome measure was the number of participants with adverse events, efficacy outcomes included relapse rate, PANSS total score, and the Clinical Global ImpressionsSeverity (CGI-S) score. Relapse was defined as worsening of the PANSS total score by $30 \%$ from baseline and CGI-S $>3$; rehospitalization for worsening of psychosis; or emergence of suicidal ideation, homicidal ideation, and/or risk of harm to self or others.

\section{Relapse}

A small proportion of subjects in the study experienced a relapse $(114 / 608,19 \%)$. The rate of relapse among lurasidone-treated patients was 20\% (82/410), and that for risperidone-treated patients, $16 \%$ (32/198), yielding a number needed to treat (NNT) value of 27 (not statistically significant [ns]) in favor of risperidone (for a brief overview of NNT, see Box 1). For both treatment groups, the Kaplan-Meier estimates of the probability of relapse were less than 0.5 at month 12; therefore, the median survival time to relapse could not be calculated for either treatment group. The relapse hazard ratio comparing lurasidone vs risperidone was 1.31 (95\% confidence interval [CI]: 0.87-1.97; $P=0.194$ ). Because the study was powered to test the noninferiority of lurasidone relative to risperidone on the basis of the assumption of expected relapse rates of $35 \%$ for both treatment groups after 1 year, the noninferiority test was uninterpretable because the actual relapse rates were substantially lower than initially predicted.

\section{Other efficacy outcomes}

The PANSS total score decreased from baseline to month 12 in both the lurasidone group $(-4.7 ; 95 \% \mathrm{CI}:-6.4$ to -3.0$)$ and the risperidone group $-6.5 ; 95 \% \mathrm{CI}:-8.8$ to -4.3 ), with no significant differences between lurasidone and risperidone 


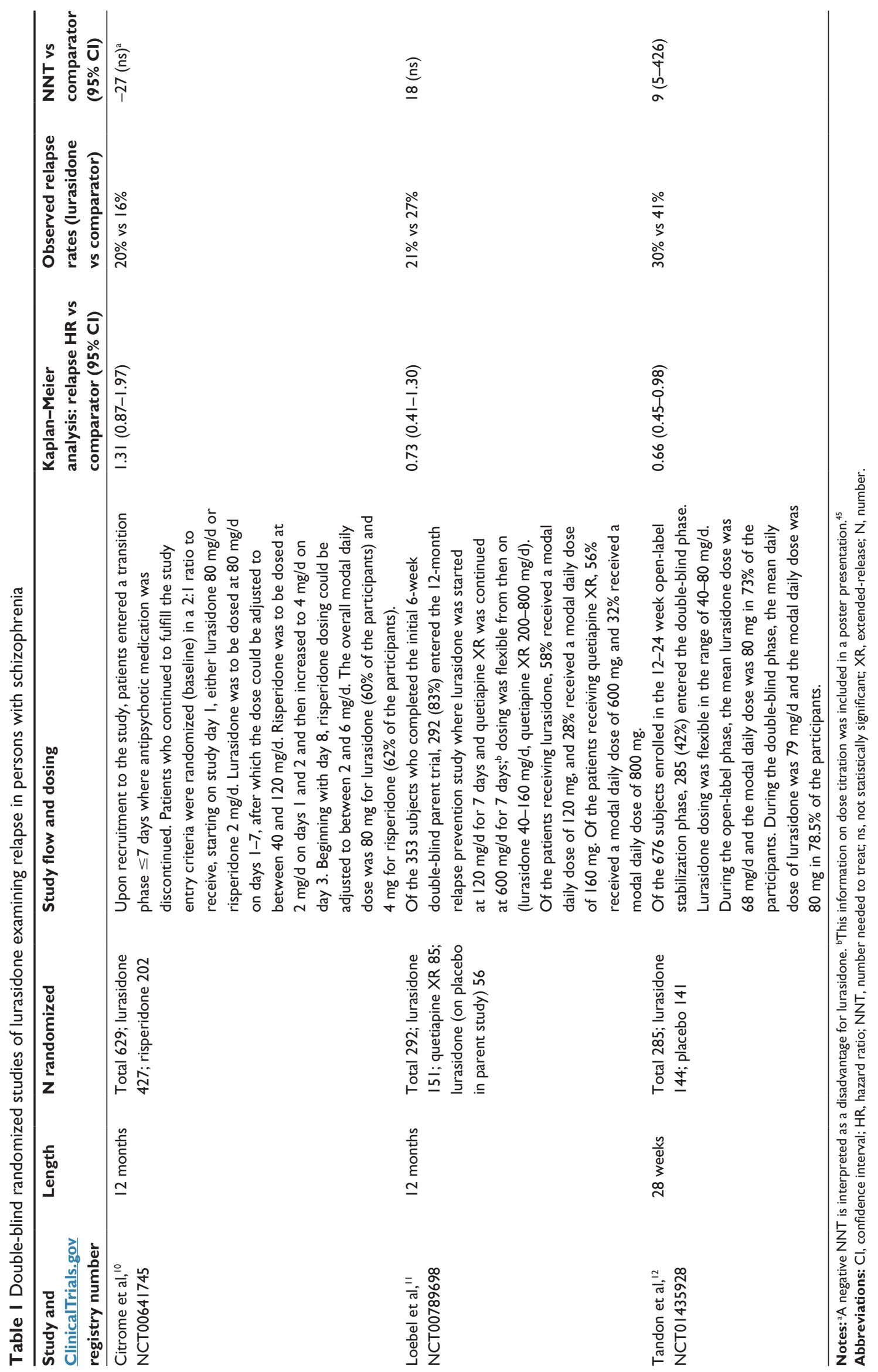




\section{Box I What is NNT?}

An NNT is a measure of effect size that is clinically intuitive. NNT answers the question: "How many patients would you need to treat with Intervention A instead of Intervention B before you would expect to encounter one additional positive outcome of interest?" For the outcome of avoidance of relapse, an NNT of " $x$ " for a test medication vs placebo would mean you would have to treat " $x$ " number of patients with the test medication instead of with placebo before expecting to avoid one additional relapse. The lower the NNT, the more robust the intervention is when compared to the alternative. NNT is a different concept than P-value, which relates to "statistical" significance. NNT is a measure of "clinical" significance. A $P$-value, even as low as $P<0.0000 \mathrm{I}$, does not necessarily mean that a result is clinically relevant. To determine possible clinical relevance (ie, clinical significance) effect size, such as NNT, needs to be evaluated.

NNT is simple to calculate:

$A=$ frequency of outcome for Intervention $A$

$B=$ frequency of outcome for Intervention $B$

NNT $=I /(A-B)$, rounded up to a whole number

For example, if giving a test medication results in relapse of $25 \%$ over a 12 -month period and giving placebo results in relapse of $50 \%$ over a 12 month period, NNT for avoidance of relapse for the test medication vs placebo is $I /(50 \%-25 \%)=I /(0.50-0.25)=I /(0.25)=4$. Thus, for every four persons given the test medication instead of placebo, you would expect to avoid one additional relapse event.

A rule of thumb is that NNT values vs placebo $<10$ denote potentially useful interventions. Most psychotropic medications for most indications have NNT values between 3 and 9 for clinically relevant definitions of response or efficacy. The lower the NNT, the more often desired outcomes are encountered.

An additional tutorial for the use of NNT can be found at http://www.ncbi.nlm.nih.gov/pmc/articles/PMC4I40623/ and guidance on interpretation is further available at http://onlinelibrary.wiley.com/doi// 0.1 I I / /ijcp. I2I $42 /$ full. Both of these resources are free to access.

Abbreviation: NNT, number needed to treat.

in the PANSS total scores at any time during the 12-month double-blind treatment period. Similarly, the CGI-S score decreased from baseline to month 12 similarly in both the lurasidone group $(-0.4 ; 95 \% \mathrm{CI}:-0.5$ to -0.3$)$ and the risperidone group $(-0.4 ; 95 \% \mathrm{CI}:-0.5$ to -0.2$)$.

\section{Tolerability outcomes}

The three most frequent adverse events among the lurasidonetreated patients (vs risperidone) were nausea (17\% vs 11\%), insomnia ( $16 \%$ vs $13 \%$ ), and sedation (15\% vs $14 \%)$; the three most frequent adverse events in the risperidone-treated patients (vs lurasidone) were increased weight (20\% vs $9 \%$ ), somnolence ( $18 \%$ vs $14 \%$ ), and headache (15\% vs $10 \%)$. The rates of akathisia reported by patients as an adverse event were $14 \%$ and $8 \%$ in the lurasidone and the risperidone groups, respectively; rates of discontinuation because of akathisia were low in both groups (1.0\% of lurasidone patients and $1.5 \%$ of risperidone patients). Risperidone was more likely to result in body weight gain of $\geq 7 \%$, as observed in $14 \%$ of subjects receiving risperidone vs $7 \%$ for lurasidone-treated patients. Endpoint change in prolactin was also higher with the risperidone group. All-cause discontinuation rates were higher for lurasidone vs risperidone: 269/419 (64\%) for lurasidone and 105/202 (52\%) for risperidone in the safety population, resulting in an NNT of $9(95 \%$ CI: 5-26) in favor of risperidone. However, there were no significant treatment differences for the time to discontinuation because of insufficient clinical response, an adverse event, or withdrawal of consent.

\section{NCT00789698}

A second long-term study that contrasted lurasidone with an active comparator was a 12-month double-blind extension $^{11}$ to a 6-week placebo-controlled acute treatment trial. ${ }^{14}$ Enrolled were 292 persons with schizophrenia, aged between 18 and 75 years, who received either flexibly dosed lurasidone 40-160 mg/d (n=207) or quetiapine XR 200-800 mg/d $(\mathrm{n}=85) .{ }^{11}$ The study was conducted at 58 centers in six countries, with approximately one-quarter of all participants being from the United States. The primary relapse prevention analysis population was defined as all subjects who were randomized to either once-daily fixed doses of lurasidone ( 80 or $160 \mathrm{mg}$ ) or quetiapine XR $600 \mathrm{mg}$ in the initial 6 week acute treatment study and who met clinical response criteria at the end of that study. Response was defined as $\geq 20 \%$ reduction in PANSS total score from acute study baseline and a CGI-S $\leq 4$. A total of 139 subjects receiving lurasidone and 79 subjects receiving quetiapine XR were included in the primary noninferiority analysis for relapse prevention. Relapse was defined as worsening of $\geq 30 \%$ in the PANSS total score from day 42 of the initial acute treatment study and a CGI-S $\geq 3$; rehospitalization for worsening of psychosis; or emergence of suicidal ideation, homicidal ideation, and/ or risk of harm.

\section{Relapse}

The rate of relapse among lurasidone-treated patients was $21 \%(29 / 139)$, and that for quetiapine-treated patients, $27 \%$ (21/79), yielding a number NNT of 18 (not statistically 
significant) in favor of lurasidone. For both treatment groups, the Kaplan-Meier estimates of the probability of relapse were less than 0.5 at month 12 ; therefore, the median survival time to relapse could not be calculated for either treatment group. The relapse hazard ratio comparing lurasidone vs quetiapine was 0.73 (95\% CI: 0.41-1.30), demonstrating noninferiority.

\section{Other efficacy outcomes}

An advantage was found for lurasidone regarding hospitalization risk. The Kaplan-Meier estimate of the probability of hospitalization at 12 months was significantly lower for lurasidone vs quetiapine XR, at $10 \%$ vs $23 \%$ (NNT 8; 95\% CI: $5-37 ; P<0.05)$, resulting in a hazard ratio of 0.43 (95\% CI: 0.19-1.0). More patients on lurasidone achieved remission, as defined by Andreasen et al, ${ }^{15}$ compared to patients receiving quetiapine XR with rates of $62 \%$ vs $46 \%$, respectively, resulting in an NNT of 7 (95\% CI: 4-52). There was significantly greater change in the PANSS total score from the 12-month study baseline for lurasidone-treated patients than for patients treated with quetiapine XR (-5.0 vs +1.7); however, changes in CGI-S scores were similar.

\section{Tolerability outcomes}

The three most frequent adverse events in the lurasidonetreated group were akathisia (13\%), headache $(11 \%)$, and insomnia ( $8 \%$ ); the three most frequent adverse events in the quetiapine XR group were worsening of schizophrenia $(15 \%)$, insomnia $(9 \%)$, and headache $(9 \%)$. The rates of akathisia reported by patients as an adverse event were $11 \%$ and $2 \%$ in the lurasidone and the quetiapine XR groups, respectively (and 13\% among those initially on placebo in the parent study and then switched to lurasidone in the 12-month study). Quetiapine XR was more likely to result in weight gain of $\geq 7 \%$, with this outcome observed in $27.5 \%$ of subjects receiving quetiapine XR vs $14 \%$ for lurasidonetreated patients at 6 months, and $15 \%$ vs $11.5 \%$ at 12 months, respectively, for observed cases. Rates of discontinuation due to adverse events were similar: $7 \%$ for lurasidone-treated patients and $5 \%$ for patients receiving quetiapine $\mathrm{XR}$.

\section{Other publications}

Additional publications identified in PubMed.gov by searching on the ClinicalTrials.gov identifier NCT00789698 have reported on improved cognitive performance in patients treated with lurasidone compared to quetiapine XR. ${ }^{16,17}$ An economic impact study has also been published, demonstrating cost savings with lurasidone over quetiapine, driven by the lower relapse-related hospitalization rates observed with lurasidone. ${ }^{13}$

\section{NCT0I 435928}

A classic randomized withdrawal study has been published where 285 persons with schizophrenia, aged 18-75 years, met protocol-specified stabilization criteria and were randomized to receive lurasidone $40-80 \mathrm{mg} / \mathrm{d}(\mathrm{n}=144)$ or placebo $(n=141)$ for up to 28 weeks. ${ }^{12}$ The study was conducted at 71 sites in seven countries, with 45 of the study sites located in the United States and comprising approximately $70 \%$ of all participants. Subjects were initially enrolled in an open-label stabilization phase where 676 acutely ill patients received 12-24 weeks of treatment with lurasidone at a starting dose of $40 \mathrm{mg} / \mathrm{d}$, with flexible dosing permitted after 3 days up until the last 4 weeks of the stabilization period, during which no dose adjustments were permitted. Treatment with antidepressant medications or mood stabilizers was allowed in patients who had been taking a stable dose for $\geq 30$ days prior to the open-label stabilization phase baseline; however, initiation or increase in dosage of these medications during the study was prohibited. The protocol-specified stabilization criteria were that subjects maintained clinical stability for $\geq 12$ weeks during the open-label stabilization phase and had remained on a stable dose of lurasidone for 4 weeks prior to randomization. Clinical stability was defined as a PANSS total score $\leq 70$, with PANSS item scores $\leq 4$ on all positive subscale items and the general psychopathology item for uncooperativeness, and a CGI-S score $<4$. There was some flexibility to retain subjects if they had temporary increases in their total PANSS score (up to 80), CGI-S of 4, or a PANSS positive item of 5; two such events were allowed after initial attainment of the stability criteria, except during the last 4 weeks of the open-label stabilization phase. Once randomized, lurasidone dose was the same as the final open-label dose but adjustments within the range of lurasidone $40-80 \mathrm{mg} / \mathrm{d}$ were subsequently allowed. Relapse was defined as an increase of $\geq 25 \%$ from double-blind baseline in PANSS total score and CGI-S worsening of $\geq 1$ point for two consecutive visits no more than 10 days apart; at any single visit, a PANSS item score of $\geq 5$ (moderately severe) on hostility or uncooperativeness, or a PANSS item score of $\geq 5$ on two or more items of unusual thought content, delusions, conceptual disorganization, or hallucinatory behavior; initiation of supplemental treatment with an antipsychotic medication other than lurasidone, an increased dose of an antidepressant or mood stabilizer, an increase in lorazepam (or benzodiazepine equivalent) dose by $\geq 2 \mathrm{mg} / \mathrm{d}$ for at least 
3 days, or electroconvulsive therapy; insufficient clinical response or exacerbation of underlying disease reported as an adverse event, as determined by the study investigator; deliberate self-injury or repeated aggressive behavior, active suicidal or homicidal ideation or attempt; or psychiatric hospitalization due to worsening schizophrenia.

\section{Relapse}

The rate of relapse among lurasidone-treated patients was $30 \%(43 / 144)$, and that for placebo-treated patients, $41 \%$ (58/141), yielding an NNT of 9 (95\% CI: 5-426) in favor of lurasidone. The Kaplan-Meier estimates of the probability of relapse at week 28 were $42 \%$ for patients receiving lurasidone and $51 \%$ for the placebo group, with a median survival time to relapse of about 28 weeks for subjects receiving placebo, and it was not calculable for patients randomized to continue treatment with lurasidone. The relapse hazard ratio comparing lurasidone vs placebo was 0.66 (95\% CI: 0.45-0.98), demonstrating superiority.

\section{Other efficacy outcomes}

Patients in the placebo-treated group evidenced worsening in PANSS total and CGI-S scores compared to patients receiving lurasidone. Of note, differences in efficacy outcomes were noted when comparing US with non-US sites; lurasidone significantly delayed time to relapse in the non-US subgroup ( $\mathrm{n}=85, \log$-rank test, $P=0.010$ ) but not in the US subgroup ( $\mathrm{n}=200, \log$-rank test, $P=0.414$ ).

\section{Tolerability outcomes}

In the open-label stabilization phase, the most common adverse events were akathisia (14\%), headache (11\%), and nausea $(10 \%)$. In the double-blind phase, the three most frequent adverse events in the lurasidone-treated group were schizophrenia (8\%), insomnia (6\%), and anxiety or back pain (4\% each); the three most frequent adverse events in the placebo group were schizophrenia (9\%), insomnia (7\%), and headache (3.5\%). Rates of akathisia in the double-blind phase were $2.1 \%$ for subjects receiving lurasidone and $2.8 \%$ for those receiving placebo. The discontinuation rate due to adverse events (including the adverse event-related relapse criterion of worsening of schizophrenia) during the double-blind phase was $14 \%$ for lurasidone and $16 \%$ for placebo. Minimal changes in weight, lipids, glucose, and prolactin were observed. Moreover, in the patients treated with lurasidone, mean weight change was $-0.6 \mathrm{~kg}$ as observed across the open-label and randomized phases, with weight gain $\geq 7 \%$ and weight loss $\geq 7 \%$ experienced by a similar proportion of patients $(17.4 \%$ and $16.7 \%$, respectively). All-cause discontinuation rates were $48 \%$ and $58 \%$, for lurasidone- and placebo-treated subjects, respectively, resulting in an NNT of 10 (ns), with a Kaplan-Meier probability of all-cause discontinuation at the week 28 endpoint of $58 \%$ for the lurasidone group vs $70 \%$ for placebo (log rank test, $P=0.070$ ).

\section{Discussion}

The efficacy of lurasidone for the maintenance treatment of patients with schizophrenia was tested in three multicenter, randomized, controlled trials, ${ }^{10-12}$ including a placebo-controlled, randomized withdrawal study. ${ }^{12}$ Superiority to placebo and noninferiority to quetiapine XR has been evidenced, with an uninterpretable relapse outcome when lurasidone was compared with risperidone. Doses tested span the range of that available for lurasidone, 40-160 mg/d; however, the placebo-controlled trial was limited to $80 \mathrm{mg} / \mathrm{d} .{ }^{12}$ This is somewhat problematic as it is apparent that some patients may require higher doses in the face of inadequate response to $80 \mathrm{mg} / \mathrm{d} .{ }^{18,19}$ This limitation in lurasidone dose in the placebo-controlled randomized withdrawal study, together with possible study-conduct problems at US sites (given the lack of signal detection in the United States vs outside the United States), may have led to the observed effect size that is less robust (and less precise) than reported for other similar studies with other second-generation antipsychotics (Table 2), ${ }^{20-28}$ and as noted in a meta-analysis of placebo-controlled studies of antipsychotic agents for relapse prevention in patients with schizophrenia, which found from data published from 1962 to 2010, across 24 randomized trials, that treatments reduced relapse rates at around 1 year (7-12 months) from $64 \%$ (placebo) to $27 \%$ (risk ratio: 0.40 ; $95 \%$ CI: $0.33-0.49$; risk difference: $-39 \%$; $95 \% \mathrm{CI}:-46$ to -32 ), for an NNT of 3..$^{29,30}$ Figure 1 depicts the NNT vs placebo and 95\% CIs for the outcome of relapse (or impending relapse) from data that have been published (or recently presented) of pivotal placebo-controlled randomized withdrawal studies of the oral first-line second-generation antipsychotics (there is no available study for quetiapine immediate-release or risperidone). Indirect comparison reveals a degree of overlap for the $95 \%$ CIs among the agents, including lurasidone vs aripiprazole, brexpiprazole, cariprazine, olanzapine, paliperidone, and ziprasidone. Although there is no overlap in the $95 \%$ CIs for lurasidone vs quetiapine $\mathrm{XR}$, this indirect comparison is difficult to interpret, particularly in the face of noninferiority for probability of relapse that was observed when lurasidone 
Table 2 Placebo-controlled randomized withdrawal studies of first-line oral second-generation antipsychotics in persons with schizophrenia

\begin{tabular}{|c|c|c|c|c|c|}
\hline Antipsychotic & $\begin{array}{l}\text { Length of double- } \\
\text { blind period }\end{array}$ & $\mathbf{N}$ randomized & $\begin{array}{l}\text { Kaplan-Meier analysis: relapse } \\
\text { HR vs placebo }(95 \% \mathrm{CI})\end{array}$ & $\begin{array}{l}\text { Observed relapse } \\
\text { rates vs placebo }\end{array}$ & $\begin{array}{l}\text { NNT vs placebo } \\
(95 \% \mathrm{Cl})\end{array}$ \\
\hline Lurasidone $^{12}$ & Up to 28 weeks & 285 & $0.66(0.45-0.98)$ & $30 \%$ vs $41 \%$ & $9(5-426)$ \\
\hline Aripiprazole ${ }^{20}$ & Up to 26 weeks & 310 & $0.50(0.35-0.7 I)$ & $34 \%$ vs $57 \%$ & $5(3-9)$ \\
\hline Asenapine $^{21}$ & Up to 26 weeks & 386 & Not reported & $12 \%$ vs $47 \%$ & $3(3-4)$ \\
\hline Brexpiprazole ${ }^{22}$ & Up to 52 weeks & 202 & 0.29 (Cl not reported) & $13.5 \%$ vs $38.5 \%$ & $4(3-8)$ \\
\hline Cariprazine $^{23}$ & Up to 72 weeks & 200 & $0.45(0.28-0.73)$ & $25 \%$ vs $47.5 \%$ & $5(3-11)$ \\
\hline lloperidone ${ }^{24}$ & Up to 26 weeks & 195 & $0.21(0.12-0.37)$ & $16.5 \%$ vs $54.2 \%{ }^{\mathrm{a}}$ & $3(2-4)$ \\
\hline Olanzapine ${ }^{25}$ & Up to 52 weeks & 326 & 6 month: $0.10(0.05-0.22)$ & $4 \%$ vs $37 \%$ & $3(3-5)$ \\
\hline Paliperidone ${ }^{26}$ & Variable; no set limit & 207 & Not reported & $22 \%$ vs $51.5 \%$ & $4(3-6)$ \\
\hline Quetiapine IR & \multicolumn{5}{|c|}{ No relevant registration studies available } \\
\hline Quetiapine $X R^{27}$ & Up to 52 weeks & 197 & Interim: $0.16(0.08-0.34)$ & $12 \%$ vs $48.5 \%$ & $3(3-4)$ \\
\hline Risperidone & \multicolumn{5}{|c|}{ No relevant placebo-controlled registration studies available } \\
\hline Ziprasidone $^{28}$ & Up to 52 weeks & 294 & Not reported & $34.5 \%$ vs $61 \%$ & $4(3-8)$ \\
\hline
\end{tabular}

Notes: aPersonal Communication, Mallery Mayo, Vanda Pharmaceuticals Inc., July I3, 2016. The observed relapse rates were not reported in the published paper.

Abbreviations: $\mathrm{Cl}$, confidence interval; HR, hazard ratio; NNT, number needed to treat; IR, immediate release; XR, extended-release; N, number.

was directly compared with quetiapine XR.${ }^{11}$ An important caveat is that randomized withdrawal studies can differ substantially in terms of open-label stabilization periods (if any), stabilization criteria, length of observation, and relapse criteria. The efficacy profile for each alternative also needs to be considered within the context of tolerability and safety. ${ }^{8}$ For example, as observed in the relapse-prevention studies of lurasidone, although lurasidone was associated with generally higher rates of akathisia, quetiapine XR and risperidone were more likely to result in weight gain.
The maintenance of a therapeutic response with longterm use of lurasidone for schizophrenia is also supported by several open-label extension studies of up to 22 months in duration. ${ }^{31-33}$ The long-term effect of lurasidone $40-160 \mathrm{mg} / \mathrm{d}$ on body weight after 12 months of treatment in persons with schizophrenia was examined in a pooled analysis of 593 observed cases; ${ }^{34}$ subjects were participants from the two 12-month randomized studies reviewed here, ${ }^{10,11}$ combined with data from a 22-month open-label extension study, ${ }^{31}$ a 12 -month extension study (NCT00088621), a

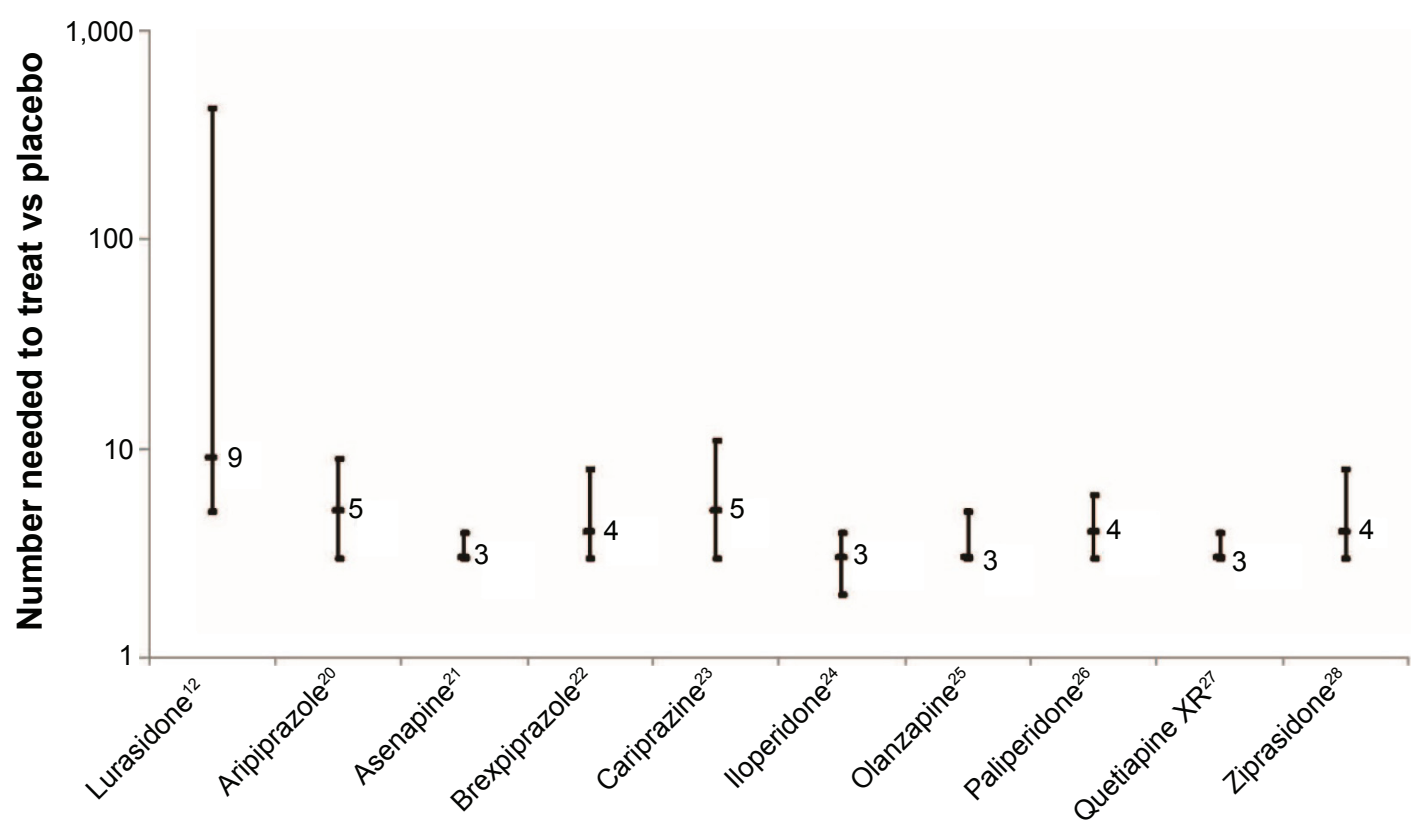

Figure I NNT vs placebo and $95 \% \mathrm{Cls}$ for the outcome of relapse (or impending relapse) from available data from the pivotal placebo-controlled randomized withdrawal studies of the oral first-line second-generation antipsychotics (there is no available study for quetiapine immediate-release or risperidone). Abbreviations: NNT, number needed to treat; $\mathrm{XR}$, extended-release; $\mathrm{Cl}$, confidence interval. 
Japanese 44-week open-label extension of a 8-week doubleblind study, and a Japanese 12-month open-label study that enrolled acute patients. Mean baseline weight was 72.8 , 80.8 , and $72.4 \mathrm{~kg}$ in the lurasidone $(n=471)$, risperidone $(n=89)$, and quetiapine XR $(n=33)$ groups, respectively. At the end of 1 year, mean weight change was $-0.4 \mathrm{~kg}$ with lurasidone, $+2.6 \mathrm{~kg}$ with risperidone, and $+1.2 \mathrm{~kg}$ with quetiapine XR. Weight gain $\geq 7 \%$ was seen in $16 \%, 26 \%$, and $15 \%$ of patients, while weight loss $\geq 7 \%$ was observed in $18.5 \%, 7 \%$, and $9 \%$, respectively. Lurasidone thus appears to have a lower risk for long-term weight gain than some other second-generation antipsychotics, and these data are consistent with that observed in short-term acute clinical trials for both schizophrenia ${ }^{35}$ and bipolar depression ${ }^{36}$ and in the 24-week open-label extension study for bipolar depression. ${ }^{37}$ Body weight is easily monitored during routine office visits, and avoiding overweight and obesity is an important strategy in managing risk for metabolic syndrome, diabetes, and cardiovascular disease. ${ }^{38}$ Patients with weight gain may be less likely to be adherent to their prescribed medications as observed in a nationwide survey of 876 US adults with schizophrenia and taking antipsychotic medication, where about $26 \%$ reported bothersome weight gain. ${ }^{39}$

Studies examining quality-of-life improvements among persons with schizophrenia treated with lurasidone have been published. ${ }^{40,41}$ In a 24 -week extension ${ }^{32}$ of an open-label 6-week switch study, ${ }^{42}$ health-related quality of life was measured using the self-reported Personal Evaluation of Transitions in Treatment scale and Short-Form 12 questionnaire; improvements were observed on both of these measures, including components assessing adherence-related attitude and psychosocial functioning. ${ }^{41}$

No singular medication is perfect for everyone. ${ }^{8}$ Additional choices for antipsychotics for the treatment of schizophrenia are also desirable to accommodate the wide range of preexisting tolerability issues that patients may have. ${ }^{43}$ Consideration should also be given to other formulations, such as longacting injectables, particularly in the maintenance phase of treatment, assuming the suitability of the currently available options for the individual person being treated. ${ }^{44}$

In summary, the overall available data support the use of lurasidone for relapse prevention. Long-term safety and tolerability mirrors that observed during short-term acute trials, with advantages in terms of a more favorable weight gain profile than many other available choices, ${ }^{6,7}$ and consequently a lower risk for problematic alterations in lipid profile and the development of insulin resistance.

\section{Disclosure}

No writing assistance or external financial support was utilized in the production of this article. In the past 36 months, Leslie Citrome has engaged in collaborative research with, or received consulting or speaking fees, from: Acadia, Alexza, Alkermes, Allergan, AstraZeneca, Avanir, Boehringer Ingelheim, BristolMyers Squibb, Eli Lilly, Forum, Genentech, Janssen, Jazz, Lundbeck, Merck, Medivation, Mylan, Neurocrine, Novartis, Noven, Otsuka, Pfizer, Reckitt Benckiser, Reviva, Shire, Sunovion, Takeda, Teva, Valeant, and Vanda. The author reports no other conflicts of interests in this work.

\section{References}

1. Robinson D, Woerner MG, Alvir JM, et al. Predictors of relapse following response from a first episode of schizophrenia or schizoaffective disorder. Arch Gen Psychiatry. 1999;56(3):241-247.

2. Wiersma D, Nienhuis FJ, Slooff CJ, Giel R. Natural course of schizophrenic disorders: a 15-year follow up of a Dutch incidence cohort. Schizophr Bull. 1998;24(1):75-85.

3. Emsley R, Chiliza B, Asmal L, Harvey BH. The nature of relapse in schizophrenia. BMC Psychiatry. 2013;13:50.

4. Muench J, Hamer AM. Adverse effects of antipsychotic medications. Am Fam Physician. 2010;81(5):617-622.

5. Bruijnzeel D, Suryadevara U, Tandon R. Antipsychotic treatment of schizophrenia: an update. Asian J Psychiatr. 2014;11:3-7.

6. Leucht S, Cipriani A, Spineli L, et al. Comparative efficacy and tolerability of 15 antipsychotic drugs in schizophrenia: a multiple-treatments meta-analysis. Lancet. 2013;382(9896):951-962.

7. Citrome L. A review of the pharmacology, efficacy and tolerability of recently approved and upcoming oral antipsychotics: an evidence-based medicine approach. CNS Drugs. 2013;27(11):879-911.

8. Volavka J, Citrome L. Oral antipsychotics for the treatment of schizophrenia: heterogeneity in efficacy and tolerability should drive decisionmaking. Expert Opin Pharmacother. 2009;10(12):1917-1928.

9. Loebel A, Citrome L. Lurasidone: a novel antipsychotic agent for the treatment of schizophrenia and bipolar depression. BJPsych Bull. 2015;39(5):237-241.

10. Citrome L, Cucchiaro J, Sarma K, et al. Long-term safety and tolerability of lurasidone in schizophrenia: a 12-month, double-blind, activecontrolled study. Int Clin Psychopharmacol. 2012;27(3):165-176.

11. Loebel A, Cucchiaro J, Xu J, Sarma K, Pikalov A, Kane JM. Effectiveness of lurasidone vs. quetiapine XR for relapse prevention in schizophrenia: a 12-month, double-blind, noninferiority study. Schizophr Res. 2013;147(1):95-102.

12. Tandon R, Cucchiaro J, Phillips D, et al. A double-blind, placebocontrolled, randomized withdrawal study of lurasidone for the maintenance of efficacy in patients with schizophrenia. J Psychopharmacol. 2016;30(1):69-77.

13. Rajagopalan K, O’Day K, Meyer K, Pikalov A, Loebel A. Annual cost of relapses and relapse-related hospitalizations in adults with schizophrenia: results from a 12-month, double-blind, comparative study of lurasidone vs quetiapine extended-release. J Med Econ. 2013; 16(8):987-996.

14. Loebel A, Cucchiaro J, Sarma K, et al. Efficacy and safety of lurasidone $80 \mathrm{mg} /$ day and $160 \mathrm{mg} /$ day in the treatment of schizophrenia: a randomized, double-blind, placebo- and active-controlled trial. Schizophr Res. 2013;145(1-3):101-109.

15. Andreasen NC, Carpenter WT Jr, Kane JM, Lasser RA, Marder SR, Weinberger DR. Remission in schizophrenia: proposed criteria and rationale for consensus. Am J Psychiatry. 2005;162(3):441-449. 
16. Harvey PD, Siu CO, Ogasa M, Loebel A. Effect of lurasidone dose on cognition in patients with schizophrenia: post-hoc analysis of a long-term, double-blind continuation study. Schizophr Res. 2015; 166(1-3):334-338.

17. Harvey PD, Siu CO, Hsu J, Cucchiaro J, Maruff P, Loebel A. Effect of lurasidone on neurocognitive performance in patients with schizophrenia: a short-term placebo- and active-controlled study followed by a 6-month double-blind extension. Eur Neuropsychopharmacol. 2013;23(11):1373-1382.

18. Loebel A, Citrome L, Correll CU, Xu J, Cucchiaro J, Kane JM. Treatment of early non-response in patients with schizophrenia: assessing the efficacy of antipsychotic dose escalation. BMC Psychiatry. 2015; $15: 271$.

19. Loebel A, Silva R, Goldman R, et al. Lurasidone dose escalation in early nonresponding patients with schizophrenia: a randomized, placebo-controlled study. J Clin Psychiatry. 2016 July 19. Epub ahead of print.

20. Pigott TA, Carson WH, Saha AR, et al. Aripiprazole for the prevention of relapse in stabilized patients with chronic schizophrenia: a placebocontrolled 26-week study. J Clin Psychiatry. 2003;64(9):1048-1056.

21. Kane JM, Mackle M, Snow-Adami L, Zhao J, Szegedi A, Panagides J. A randomized placebo-controlled trial of asenapine for the prevention of relapse of schizophrenia after long-term treatment. J Clin Psychiatry. 2011;72(3):349-355.

22. Fleischhacker WW, Hobart M, Ouyang J, et al. Brexpiprazole (OPC34712) efficacy and safety as maintenance therapy in adults with schizophrenia: randomized, double-blind, placebo-controlled study. Eur Neuropsychopharmacol. 2015;25 (Suppl 2):S527.

23. Durgam S, Earley W, Li R, et al. Long-term cariprazine treatment for the prevention of relapse in patients with schizophrenia: a randomized, double-blind, placebo-controlled trial. Schizophr Res. 2016 July 14. Epub ahead of print.

24. Weiden PJ, Manning R, Wolfgang CD, et al. A randomized trial of iloperidone for prevention of relapse in schizophrenia: the REPRIEVE study. CNS Drugs. Epub July 5, 2016.

25. Beasley CM Jr, Sutton VK, Hamilton SH, et al. A double-blind, randomized, placebo-controlled trial of olanzapine in the prevention of psychotic relapse. J Clin Psychopharmacol. 2003;23(6):582-594.

26. Kramer M, Simpson G, Maciulis V, et al. Paliperidone extended-release tablets for prevention of symptom recurrence in patients with schizophrenia: a randomized, double-blind, placebo-controlled study. J Clin Psychopharmacol. 2007;27(1):6-14

27. Peuskens J, Trivedi J, Malyarov S, et al. Prevention of schizophrenia relapse with extended release quetiapine fumarate dosed once daily: a randomized, placebo-controlled trial in clinically stable patients. Psychiatry (Edgmont). 2007;4(11):34-50.

28. Arato M, O'Connor R, Meltzer HY; ZEUS Study Group. A 1-year, doubleblind, placebo-controlled trial of ziprasidone 40,80 and $160 \mathrm{mg} / \mathrm{day}$ in chronic schizophrenia: the Ziprasidone Extended Use in Schizophrenia (ZEUS) study. Int Clin Psychopharmacol. 2002;17(5):207-215.

29. Leucht S, Tardy M, Komossa K, Heres S, Kissling W, Davis JM. Maintenance treatment with antipsychotic drugs for schizophrenia. Cochrane Database Syst Rev. 2012;(5):CD008016.

30. Leucht S, Tardy M, Komossa K, et al. Antipsychotic drugs versus placebo for relapse prevention in schizophrenia: a systematic review and meta-analysis. Lancet. 2012;379(9831):2063-2071.
31. Correll CU, Cucchiaro J, Silva R, Hsu J, Pikalov A, Loebel A. Long-term safety and effectiveness of lurasidone in schizophrenia: a 22-month, open-label extension study. CNS Spectr. Epub April 6, 2016.

32. Citrome L, Weiden PJ, McEvoy JP, et al. Effectiveness of lurasidone in schizophrenia or schizoaffective patients switched from other antipsychotics: a 6-month, open-label, extension study. CNS Spectr. 2014;19(4):330-339.

33. Stahl SM, Cucchiaro J, Simonelli D, Hsu J, Pikalov A, Loebel A. Effectiveness of lurasidone for patients with schizophrenia following 6 weeks of acute treatment with lurasidone, olanzapine, or placebo: a 6-month, open-label, extension study. J Clin Psychiatry. 2013;74(5):507-515.

34. Meyer JM, Mao Y, Pikalov A, Cucchiaro J, Loebel A. Weight change during long-term treatment with lurasidone: pooled analysis of studies in patients with schizophrenia. Int Clin Psychopharmacol. 2015;30(6):342-350.

35. Citrome L. Lurasidone for the acute treatment of adults with schizophrenia: what is the number needed to treat, number needed to harm, and likelihood to be helped or harmed? Clin Schizophr Relat Psychoses. 2012;6(2):76-85.

36. Citrome L, Ketter TA, Cucchiaro J, Loebel A. Clinical assessment of lurasidone benefit and risk in the treatment of bipolar I depression using number needed to treat, number needed to harm, and likelihood to be helped or harmed. J Affect Disord. 2014;155:20-27.

37. Ketter TA, Sarma K, Silva R, Kroger H, Cucchiaro J, Loebel A. Lurasidone in the long-term treatment of patients with bipolar disorder: a 24-week open-label extension study. Depress Anxiety. 2016;33(5): 424-434.

38. Citrome L, Blonde L, Damatarca C. Metabolic issues in patients with severe mental illness. South Med J. 2005;98(7):714-720.

39. Dibonaventura M, Gabriel S, Dupclay L, Gupta S, Kim E. A patient perspective of the impact of medication side effects on adherence: results of a cross-sectional nationwide survey of patients with schizophrenia. BMC Psychiatry. 2012;12:20.

40. Awad G, Hassan M, Loebel A, Hsu J, Pikalov A, Rajagopalan K. Healthrelated quality of life among patients treated with lurasidone: results from a switch trial in patients with schizophrenia. BMC Psychiatry. 2014;14:53.

41. Awad G, Ng-Mak D, Rajagopalan K, Hsu J, Pikalov A, Loebel A. Long-term health-related quality of life improvements among patients treated with lurasidone: results from the open-label extension of a switch trial in schizophrenia. BMC Psychiatry. 2016;16:176.

42. McEvoy JP, Citrome L, Hernandez D, et al. Effectiveness of lurasidone in patients with schizophrenia or schizoaffective disorder switched from other antipsychotics: a randomized, 6-week, open-label study. J Clin Psychiatry. 2013;74(2):170-179.

43. Citrome L, Eramo A, Francois C, et al. Lack of tolerable treatment options for patients with schizophrenia. Neuropsychiatr Dis Treat. 2015;11:3095-3104.

44. Citrome L. New second-generation long-acting injectable antipsychotics for the treatment of schizophrenia. Expert Rev Neurother. 2013 ; 13(7):767-783.

45. Loebel A, Cucchiaro J, Xu J, Sarma K, Pikalov A, Kane JM. Effectiveness of lurasidone vs. quetiapine XR for relapse prevention in schizophrenia: a 12-month, double-blind study. Poster presented at: American Psychiatric Association Annual Meeting, May 5-9, 2012, Philadelphia, PA, USA.
Patient Preference and Adherence

\section{Publish your work in this journal}

Patient Preference and Adherence is an international, peer-reviewed, open access journal that focuses on the growing importance of patient preference and adherence throughout the therapeutic continuum. Patient satisfaction, acceptability, quality of life, compliance, persistence and their role in developing new therapeutic modalities and compounds to optimize

\section{Dovepress}

clinical outcomes for existing disease states are major areas of interest for the journal. This journal has been accepted for indexing on PubMed Central. The manuscript management system is completely online and includes a very quick and fair peer-review system, which is all easy to use. Visit http://www. dovepress.com/testimonials.php to read real quotes from published authors. 